\title{
Modeling Inoculum Availability of Plurivorosphaerella nawae in Persimmon Leaf Litter with Bayesian Beta Regression
}

\author{
Joaquín Martínez-Minaya, ${ }^{1}$ David Conesa, ${ }^{2}$ Antonio López-Quílez, ${ }^{2}$ José Luís Mira, ${ }^{3}$ and Antonio Vicent ${ }^{3, \dagger}$ \\ ${ }^{1}$ Basque Center for Applied Mathematics, Mazarredo, 14 E48009 Bilbao, Basque Country, Spain \\ ${ }^{2}$ Departament d'Estadística i Investigació Operativa, Universitat de València, Burjassot, 46500 València, Spain \\ ${ }^{3}$ Centre de Protecció Vegetal i Biotecnologia, Institut Valencià d'Investigacions Agràries, Moncada, 46113 València, Spain \\ Accepted for publication 20 November 2020.
}

\begin{abstract}
Circular leaf spot (CLS), caused by Plurivorosphaerella nawae, is a serious disease affecting persimmon (Diospyros kaki) that is characterized by necrotic lesions on leaves, defoliation, and fruit drop. Under Mediterranean conditions, $P$. nawae forms pseudothecia in the leaf litter in winter, and ascospores are released in spring, infecting susceptible leaves. Persimmon growers are advised to apply fungicides for CLS control during the period of inoculum availability, which was previously defined based on ascospore counts under the microscope. A model of inoculum availability of $P$. nawae was developed and evaluated as an alternative to ascospore counts. Leaf litter samples were collected weekly in L'Alcúdia (Spain) from 2010 to 2015. Leaves were soaked and placed in a wind tunnel, and the released ascospores of $P$. nawae were counted. Hierarchical Bayesian beta regression methods were used to model the dynamics of ascospore production in the leaf litter. The
\end{abstract}

ABSTRACT selected model included accumulated degree-days (ADDs) and ADDs taking into account the vapor pressure deficit (ADDvpd) as fixed effects and year as random effect. This model had a mean absolute error of 0.042 and a root mean square error of 0.062 . The beta regression model was evaluated in four orchards from 2010 to 2015. Higher accuracy was obtained at the beginning and the end of the ascospore production period, which are the events of interest to schedule fungicide sprays for CLS control in Spain. This same modeling framework can be extended to other fungal plant pathogens whose inoculum dynamics are expressed as proportion data.

Keywords: decision support system, ecology and epidemiology, integrated nested Laplace approximation (INLA), mycology, Mycosphaerella nawae, warning system
Circular leaf spot (CLS) of persimmon (Diospyros kaki Thunb.), caused by Plurivorosphaerella nawae (Hiura \& Ikata) O. Hassan \& T. Chang (三 Mycosphaerella nawae Hiura \& Ikata), induces necrotic lesions on leaves, chlorosis, and defoliation. The presence of foliar lesions and premature leaf drop leads to early fruit maturation and abscission, resulting in serious economic losses (Bassimba et al. 2017). The disease was first described in humid areas of Japan and Korea (Ikata and Hitomi 1929; Kang et al. 1993). The detection of CLS in eastern Spain was the first report of the disease in a semiarid area (Vicent et al. 2012).

The fungus forms pseudothecia in leaf litter in winter, from which ascospores are produced as temperatures increase in spring (Kang et al. 1993). Ascospores are wind dispersed and infect persimmon leaves in the presence of a film of water and adequate temperatures. Studies in Korea and Spain indicate that infections occur whenever airborne ascospores are present (Kang et al. 1993; Vicent et al. 2012). The main infection period was from mid-May to the end of July in Korea (Kang et al. 1993; Kwon and Park 2004) and from the beginning of April to early July in Spain, coinciding with shoot development, flowering, and fruit set (Vicent et al. 2012). The asexual stage of $P$. nawae was originally identified in Korea,

†Corresponding author: A. Vicent; vicent_antciv@gva.es

Funding: Research was funded by the Instituto Nacional de Investigación y Tecnología Agraria y Alimentaria (INIA), Ministerio de Ciencia e Innovación (MICINN) via research grants RTA2013-00004-C03-02-FEDER and RTA201700009-C04-02-FEDER. D.C. and A.L.Q. thank MICINN for financial support (jointly financed by the European Regional Development Fund) via research grants PID2019-106341GB-I100 and TEC2016-81900-REDT. J.M.-M. thanks the Basque Government for support through the BERC 2018-2021 program and through the MICINN: BCAM Severo Ochoa accreditation SEV-2017-0718.

The author(s) declare no conflict of interest.

Copyright (c) 2021 The Authors. This is an open access article distributed under the CC BY 4.0 International license. but the role of conidia in field epidemics is not fully understood (Kwon et al. 1998; Kwon and Park 2004). In Spain, this secondary inoculum has not been observed (Vicent et al. 2012). The disease is characterized by a long incubation period of about 4 months (Kwon and Park 2004; Vicent et al. 2012).

Fungicide schedules for the control of CLS in Korea consist of three to four foliar applications during the infection period. Although the efficacy of fungicide programs may differ between years, effective disease control was obtained under experimental conditions (Kwon et al. 1998; Kwon and Park 2004). In Spain, two to four fungicide applications during the infection period in spring also showed good efficacy for the control of CLS, whereas postinfection sprays applied after the inoculum season were ineffective (Bassimba et al. 2017; Berbegal et al. 2013). Cultural practices, such as leaf litter removal and moving from flood to drip irrigation systems, are also recommended to growers, but their efficacy has not been quantified to date (Vicent et al. 2011, 2012).

Fungicide programs are effective for CLS control only when spray applications coincide with the infection period, defined by the presence of ascospores, adequate environmental conditions, and susceptible leaves. The presence of airborne spores is typically monitored with active volumetric or passive spore traps (West and Kimber 2015). Nevertheless, the predictive ability of spore traps is limited because they detect the ascospores only when they have been released into the air in the orchard. In the case of P. nawae in Spain, monitoring inoculum production in the leaf litter made it possible to predict the dynamics of airborne ascospores 1 to 2 weeks in advance, so this method is routinely used by the advisory services to schedule fungicide sprays for CLS control (Vicent et al. 2012). Samples of leaf litter are collected weekly in affected persimmon orchards and soaked in distilled water. Immediately after soaking, leaves are placed in a wind tunnel until they are dry. Ascospores released from the leaf litter are collected on glass microscope slides and counted with the aid of a microscope (Vicent et al. 2011). Inoculum 
monitoring in the leaf litter is typically initiated in January and continues until early summer, once the ascospore deposit is completely depleted. Although this method proved to be useful, it is time- and resource-consuming and requires specific laboratory equipment and qualified personnel. Consequently, the extent of the monitored area and the density of the sampling network are limited.

Models for inoculum maturation in the leaf litter have been developed for several ascomycetes as a more efficient alternative to ascospore counts (De Wolf and Isard 2007). Most of these models rely on transformations of the response variable and are then fitted as a linear regression (Luley and McNabb 1991; Spotts and Cervantes 1994). For instance, Gadoury and MacHardy (1982b) used a linear regression with a probit transformation to the proportion of ascospore discharge. Villalta et al. (2001) used a linear regression with a logit transformation. This same transformation was used by Choi et al. (2018) for P. nawae ascospores in Korea. Rossi et al. (2009) and Eikemo et al. (2011) compared linear regressions with asymptotic, monomolecular, logistic, and Gompertz transformations. In other cases, nonlinear regression analysis was used (Cooley et al. 2007; Legler et al. 2014; Navas-Cortés et al. 1998b; Rossi et al. 1999). Nevertheless, when the proportion of ascospores is the variable being modeled, other methods are available, such as the beta regression model (Ferrari and Cribari-Neto 2004). Basically, this method assumes that the response variable conditioned to the linear predictor follows a beta distribution.

Beta regression is widely applied in many scientific disciplines but has been used only to a limited extent in plant pathology. Busby et al. (2013) used beta regression to evaluate the effects of fungal endophytes and Populus genotypes on the proportion of leaf area affected by Drepanopeziza populi. Yellareddygari et al. (2016) developed a beta regression model to predict the incidence of pink rot, caused by Phytophthora erythroseptica, on potato tubers during storage based on disease incidence at harvest. Burman et al. (2017) estimated the potential geographic distribution of Austropuccinia psidii in Puerto Rico with beta regression. More recently, Xu et al. (2019) related the proportion of wheat plants carrying overwintered Puccinia striiformis f. sp. tritici with temperature-derived variables via beta regression.

Bayesian hierarchical methods are becoming popular in many fields, because they may better address the intrinsic complexity typical of many natural systems (Clark 2005). In Bayesian inference, parameters are treated as random variables, and the posterior distribution is obtained by combining the prior distribution and the likelihood function. However, getting the posterior distribution is not always straightforward, and numerical algorithms are usually needed. Markov chain Monte Carlo (MCMC) methods (Gilks et al. 1996) are widely used to obtain posterior distributions, but they involve computationally and time-intensive simulations. The integrated nested Laplace approximation (INLA) approach was developed as a computationally efficient alternative to MCMC in latent Gaussian models (Rue et al. 2009; Tierney and Kadane 1986).

In this work, we used hierarchical Bayesian beta regression models with fixed and random effects to estimate the production of $P$. nawae ascospores in persimmon leaf litter via the INLA method. The resulting model will help to predict the dynamics of $P$. nawae inoculum in the leaf litter based on environmental covariates, without direct quantification of ascospores. This method should facilitate wider implementation of a decision support system to optimize the fungicide programs for CLS control in Spain.

\section{MATERIALS AND METHODS}

Field data. The model was developed from 2010 to 2015 in a 0.83 ha orchard of persimmon cultivar Rojo Brillante severely affected by CLS in L'Alcúdia, in the province of Valencia, Spain. Trees were 11 years old at the beginning of the study and were grafted on Diospyros lotus L. rootstock. The orchard was drip irrigated and had a north-south row orientation with 5-m across-row spacing and 4-m in-row spacing. Orchards of similar characteristics were selected in the province of Valencia in Benimodo, Villanueva de Castellón, and Guadassuar (2010 and 2011) and in Moncada (2012 to 2015) for model evaluation (i.e., validation). Orchard characteristics were representative of commercial persimmon plantings in the region (Malagón 2015). In all cases, an experimental area of 0.2 hectares $(10 \times 10$ trees $)$ in the center of each orchard was kept free of fungicide applications during the study period.

Environmental data were monitored hourly in each orchard with an automated meteorological station (Hobo U30, Onset Computer Corp.) including sensors for temperature and relative humidity (Hobo S-THB, accuracies $\pm 0.2^{\circ} \mathrm{C}, \pm 2.5 \%$ ) and rainfall (7852, Davis Instruments Corp, resolution $0.2 \mathrm{~mm}$ ). Environmental monitors were located $1.5 \mathrm{~m}$ above the soil surface within the row in the center of the experimental area.

Following Rossi et al. (2009), time was expressed in physiological units calculated by three different methods, all of them based on sums of the daily mean air temperatures exceeding $0^{\circ} \mathrm{C}$ (i.e., $T_{\text {base }}=0^{\circ} \mathrm{C}$ ). In particular, accumulated degree-days (ADDs) were calculated as

$$
A D D_{i}=\sum_{j=\text { biofix }}^{N(i)} T_{j}
$$

where $i$ and $j$ are the subscripts for observations and days, respectively, varying between 1 January (selected as biofix in this study) and the number of days until time $i, N(i)$, and $T_{j}$ is the air temperature for each day (calculated as the mean of 24 hourly values in ${ }^{\circ} \mathrm{C}$ ) if $T_{j}>0$, otherwise $T_{j}=0$.

Second, ADD considering vapor pressure deficit (ADDvpd) was calculated as follows:

$$
\text { ADDvpd }_{i}=\sum_{j=\text { biofix }}^{N(i)} T_{j} \cdot V P D_{j}
$$

where $i$ is the subscript for observation and $j$ is the subscript for days, varying between the biofix and the number of days until time $i, N(i)$, and $T_{j}$ is the air temperature on each day (calculated as the mean of 24 hourly values in ${ }^{\circ} \mathrm{C}$ ) if $T_{j}>0$, otherwise $T_{j}=0$. Here $\mathrm{VPD}_{j}$ is a binary variable calculated as follows: When vapor pressure deficit $\operatorname{vpd}_{j} \leq 4 \mathrm{hPa}, \mathrm{VPD}_{j}=1$, otherwise $\mathrm{VPD}_{j}=0$, with vpd calculated from temperature and relative humidity (rh, \%) as shown in the following formula:

$$
(v p d)_{j}=\left(1-\frac{r h_{j}}{100}\right) \cdot 6.11 \cdot \exp \left(\frac{17.47 \cdot T_{j}}{239+T_{j}}\right)
$$

Finally, a variable that incorporates information about rainfall was also considered. It was denoted as ADDwet and corresponds to ADDs but takes into account both the daily vpd and rainfall $(R)$ :

$$
\text { ADDwet }_{i}=\sum_{j=\text { biofix }}^{N(i)} T_{j} \cdot W E T_{j}
$$

where $i$ is the observation and $j$ the subscript for days, with $j=$ biofix to $N(i)$, and $T_{j}$ is the air temperature on each day (calculated as the mean of 24 hourly values) if $T_{j}>0$, otherwise $T_{j}=0$. $\mathrm{WET}_{j}$ is a binary variable calculated as follows: When $R_{j} \geq 0.2 \mathrm{~mm}$ per day and $\operatorname{vpd}_{i} \leq 4 \mathrm{hPa}, \mathrm{WET}_{j}=1$, otherwise $\mathrm{WET}_{j}=0$. Thresholds used for vpd and $R$ were defined by Rossi et al. (2009), to account for the presence of moisture in the leaf litter.

The dynamics of $P$. nawae ascospore production in the leaf litter was studied in the orchards and years indicated previously. Dry persimmon leaves on the orchard floor were covered with a plastic net $\left(2 \times 2 \mathrm{~m}^{2}, 5\right.$ - by 5 -mm openings) fixed with four stainless-steel pins. Plastic nets were located in the center of the experimental area in each orchard without covering the soil area wetted by the drip irrigation system. Leaf litter density under the plastic nets was adjusted to $350 \mathrm{~g}$ of dry leaves $/ \mathrm{m}^{2}$ (Vicent et al. 2011). A pooled 
sample of 20 dry leaves was collected weekly in each orchard, but four samples of 20 dry leaves were collected in L'Alcúdia from 2013 to 2015. Leaf litter samples were soaked for $15 \mathrm{~min}$ in distilled water. Immediately after soaking, leaves were placed with the abaxial surface facing upward in a wind tunnel. The device consisted of an aluminum tray $640 \mathrm{~mm}$ long, $300 \mathrm{~mm}$ wide, and 60 $\mathrm{mm}$ deep. One end had two tubes through which air was introduced by a pump. The other end was tapered to a vent ( $9 \mathrm{~mm}$ in diameter) to which a glass microscope slide $(26 \times 76 \mathrm{~mm})$ coated with silicone oil (CAS no. 63148-62-9, Merck) with a viscosity of 100 $\mathrm{mPa} / \mathrm{s}$ was attached at $20 \mathrm{~mm}$. Wind speed at the vent was adjusted to about $3.5 \mathrm{~m} / \mathrm{s}$ (Vicent et al. 2011; Whiteside 1974). The wind tunnel operated for $30 \mathrm{~min}$ until the leaves were visibly dry. During the process, air and water temperatures were maintained at about $21^{\circ} \mathrm{C}$ (Vicent et al. 2011).

Discharged ascospores collected on the glass microscope slide were stained with lactophenol acid cotton blue and examined at $400 \times$ magnification. All ascospores showing the morphological characteristics of $P$. nawae (i.e., spindle-shaped, 10 to $13 \times 3$ to $4 \mu \mathrm{m}$, hyaline, two-celled, with a median or slightly supramedian septum) (Hassan and Chang 2019; Kwon et al. 1998) were counted in four microscope field transects. Isolations were arbitrarily performed each year with additional leaf litter samples, and the ejected ascospores were collected on potato dextrose agar amended with $0.5 \mathrm{~g} /$ liter of streptomycin sulfate. Identification of the resulting fungal colonies was confirmed via a nested PCR specific for P. nawae (Berbegal et al. 2013). For each discharge, the cumulative proportion of ascospores was calculated on a 0 -to-1 scale based on the total number collected from the leaf litter samples in each orchard and year.

Beta regression. Beta regression is commonly used for variables that assume values in the open interval $(0,1)$ (Ferrari and Cribari-Neto 2004). As it is common in other distributions, the beta distribution can be parametrized in terms of the mean $\mu$ and a dispersion parameter $\phi$ whereby the variance $\sigma^{2}=\frac{\mu \cdot(1-\mu)}{1+\phi}$ is dependent on the mean. The maximum variance is observed at the center of the distribution, whereas the minimum is found at the edges. In addition, the variance of the distribution, for fixed $\mu$, decreases as $\phi$ increases; in other words, they are inversely proportional.

Let $y_{i l}(i=1, \ldots, n ; l=1, \ldots, L)$ be the cumulative proportion of ascospores discharged for the $i$ th observation in year $l$, with mean $\mu_{i l}$ and unknown precision $\phi$. These variables, representing proportions (in our particular case, the cumulative proportion of ascospores discharged), can be related to the linear predictor with a link function via a similar approach to the generalized linear model. In our case, the logit function resulted in better model performance than probit and cloglog:

$$
\operatorname{logit}\left(\mu_{i l}\right)=\beta_{0}+\sum_{j=1}^{N_{\beta}} \beta_{j} x_{j i l}+v_{l}
$$

where $\beta_{0}$ is the intercept of the model; $x_{j i l}$ is the fixed effects, in this case, variables previously defined in terms of physiological units (i.e., ADD, ADDvpd, and ADDwet); $\beta_{j}$ is the parameters corresponding to the fixed effects of the model; and $v_{l}$ represents an independent structured random effect for the year. Other effects, such as spatial or spatiotemporal effects, could be incorporated in the model (Paradinas et al. 2018). In this work, models with and without the random effect year were considered. Because the beta distribution is defined in the open interval $(0,1)$, we used the transformation proposed by Smithson and Verkuilen (2006):

$$
y_{i}^{\text {new }}=\frac{y_{i} \cdot(n-1)+\frac{1}{2}}{n}
$$

to ensure that the response variable was between 0 and 1 .

Bayesian inference with INLA. A Bayesian hierarchical approach was used to fit the models to the cumulative proportion of discharged ascospores with INLA (Rue et al. 2009). This method uses Laplace approximations (Tierney and Kadane 1986) to obtain the posterior distributions in latent Gaussian models (Rue et al. 2009). The prior knowledge of the additive predictor is expressed via Gaussian prior distributions. In this context, all the latent Gaussian variables can be seen as components of a vector known as the latent Gaussian field.

Vague Gaussian distributions were used for the parameters $\beta_{j} \approx$ $N\left(0, \tau_{\beta}=10^{-3}\right)$, and an independent Gaussian distribution was considered for the random effect year $v_{j} \approx N\left(0, \tau=1 / \sigma^{2}\right)$. In this model, and respecting the hierarchy, $\tau$ and $\phi$ were considered hyperparameters. The default prior gamma $(1,0.1)$ was used for $\phi$, and penalized complexity prior (PC-prior) was established for the precision of the random effect $\tau$ according to Simpson et al. (2017), who proposed priors that penalize departure from a base model. The PC-prior favors the base model unless evidence is provided against it, departure from the base model is measured via the Kullback-Leibler distance, and penalization from the base model is done at a constant rate on the distance (Gómez-Rubio 2020). Interestingly, the PC-prior can be defined via probability statements on the model parameters in the appropriate scale. In our particular case, the PC-prior for $\tau$ was defined in terms of the square of its inverse, the standard deviation $\sigma$, such that $P(\sigma>5)=0.01$.

The computational implementation R-INLA for $\mathrm{R}$ was used to perform approximate Bayesian inference (R Core Team 2020). Pearson's correlation coefficients between ADD, ADDvpd, and ADDwet were previously calculated to assist in variable selection and to minimize potential problems of multicollinearity. Model selection was conducted based on choosing the best subset of covariates. This method evaluates all 16 possible models and chooses the best model according to information criteria (Heinze et al. 2018). In this work we used the deviance information criterion (DIC), which is a generalization of the Akaike information criterion developed for Bayesian model comparison (Spiegelhalter et al. 2002), and the Watanabe-Akaike information criterion (WAIC) (Watanabe 2010). DIC and WAIC are the sum of two components, namely quantifying model fit and evaluating model complexity. The predictive ability of the models was evaluated by leave-one-out cross-validation via the mean logarithmic conditional predictive ordinate (LCPO) (Roos and Held 2011). The conditional predictive ordinate (CPO) is a Bayesian diagnostic that detects discrepant observations. It is defined as $\mathrm{CPO}=P\left(y_{i} \mid y_{(i)}\right)$, where $y_{(i)}$ is the data omitting the $i$ th observation and $P\left(y_{i} \mid y_{(i)}\right)$ is the predictive distribution of a new observation $y_{i}$ given $y_{(i)}$ (Geisser 1980). Models with the lowest values of DIC, WAIC, and LCPO were selected. Pearson's residuals were calculated and plotted to detect potential problems of serial correlation.

Lastly, the marginal posterior densities for the parameters and predictive distributions for new observations were obtained with the best model in L'Alcúdia. Median values of the posterior predictive distribution were linearly regressed against the observed values, and $R^{2}$ was computed. The mean absolute error (MAE) and root mean square error (RMSE) were also calculated. The best model in L'Alcúdia was evaluated in Benimodo, Villanueva de Castellón, and Guadassuar (2010 and 2011) and Moncada (2012 to 2015). Likewise, the linear regression of predicted versus observed, MAE, and RMSE were calculated in each case.

\section{RESULTS}

During the study period in L'Alcúdia, annual mean temperature ranged from $16.5^{\circ} \mathrm{C}$ in 2010 to $18.2^{\circ} \mathrm{C}$ in 2014 (Fig. 1A). The lowest daily mean temperature ranged from $1.3^{\circ} \mathrm{C}$ in 2009 to $5.4^{\circ} \mathrm{C}$ in 2013 , and the highest daily mean temperature ranged from $27.8^{\circ} \mathrm{C}$ in 2013 to $32.2^{\circ} \mathrm{C}$ in 2010 . Annual mean vpd ranged from $5.8 \mathrm{hPa}$ in 2010 to $6.9 \mathrm{hPa}$ in 2013 . The lowest daily vpd was $0.2 \mathrm{hPa}$ in 2015 , and the highest daily vpd was $27.1 \mathrm{hPa}$ in 2010 . The number of days with vpd $\leq 4 \mathrm{hPa}$ ranged from 62 in 2013 to 133 in 2015. Annual rainfall ranged from $208 \mathrm{~mm}$ in 2014 to $699 \mathrm{~mm}$ in 2009. The number of days with 
rainfall $\geq 0.2 \mathrm{~mm}$ ranged from 63 in 2013 to 117 in 2010 and 2011 . Annual ADD ranged from 6,028. $0^{\circ} \mathrm{C}$-days in 2010 to $6,659.1^{\circ} \mathrm{C}$-days in 2014 (Fig. 1B). Annual ADDvpd ranged from $704.7^{\circ} \mathrm{C}$-days in 2013 to $1,764.5^{\circ} \mathrm{C}$-days in 2015 , and $\mathrm{ADDwet}$ ranged from $382.0^{\circ} \mathrm{C}$ days in 2013 to $883.5^{\circ} \mathrm{C}$-days in 2015 .
The best models for the cumulative proportion of $P$. nawae ascospores discharged from persimmon leaf litter are displayed in Table 1. Most of them included the random effect year $(v)$, and those not including the fixed effect ADD were ranked very low based on their DIC, WAIC, and LCPO values. Two of the five best
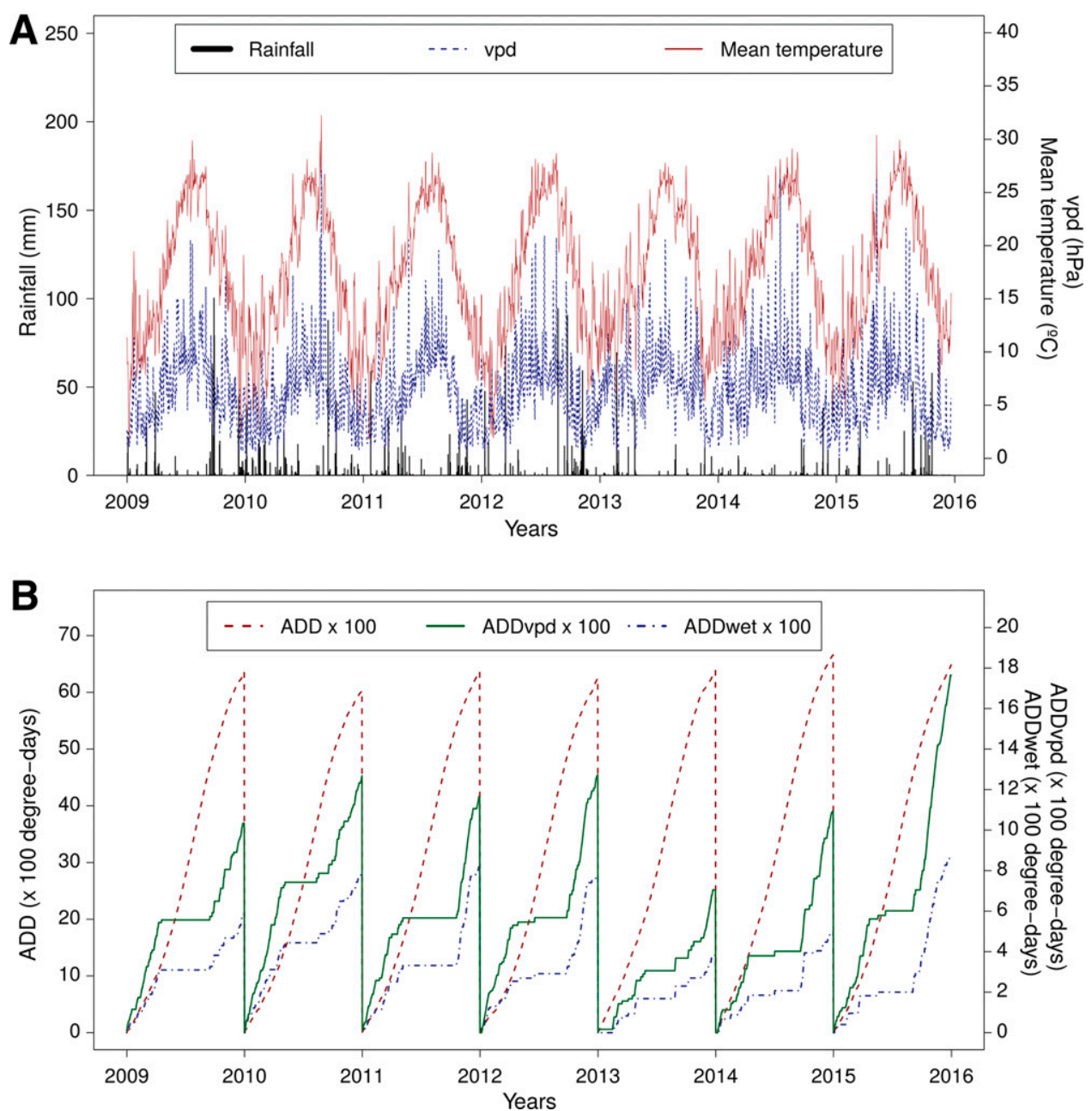

Fig. 1. Environmental conditions in the study orchard in L'Alcúdia from 2009 to 2015. A, Rainfall, vapor pressure deficit (vpd), and mean temperature; and B, accumulated degree-days (ADDs), ADDs considering vpd (ADDvpd), and ADDs considering vpd and rainfall (ADDwet).

TABLE 1. Models for the cumulative proportion of Plurivorosphaerella nawae ascospores discharged from persimmon leaf litter based on the fixed effects accumulated degree-days (ADDs), ADDs taking into account vapor pressure deficit (ADDvpd), ADDs taking into account vapor pressure deficit and rain (ADDwet), and the random effect year $(v)$

\begin{tabular}{|c|c|c|c|c|}
\hline Model no. & Model $^{\mathrm{a}}$ & $\mathrm{DIC}^{\mathrm{b}}$ & WAIC $^{\mathrm{c}}$ & $\overline{\mathrm{LCPO}^{\mathrm{d}}}$ \\
\hline 1 & $\mathrm{ADD}+\mathrm{ADDvpd}+v$ & $-1,185.39$ & $-1,183.49$ & -1.88 \\
\hline 2 & ADD + ADDwet + ADDvpd $+v$ & $-1,184.84$ & $-1,183.22$ & -1.88 \\
\hline 3 & $\mathrm{ADD}+\mathrm{ADDwet}+v$ & $-1,165.41$ & $-1,163.80$ & -1.85 \\
\hline 5 & ADD + ADDvpd & $-1,117.62$ & $-1,115.66$ & -1.77 \\
\hline 6 & $\mathrm{ADD}+\mathrm{ADDwet}+\mathrm{ADDvpd}$ & $-1,115.70$ & $-1,113.80$ & -1.77 \\
\hline 7 & $\mathrm{ADD}+\mathrm{ADDwet}$ & $-1,033.69$ & $-1,032.96$ & -1.64 \\
\hline 8 & $\mathrm{ADD}$ & -970.37 & -970.11 & -1.54 \\
\hline 11 & ADDwet $+v$ & -575.94 & -578.17 & -0.92 \\
\hline 12 & ADDwet + ADDvpd & -470.71 & -472.11 & -0.75 \\
\hline 13 & ADDvpd & -469.37 & -470.37 & -0.75 \\
\hline 14 & ADDwet & -455.96 & -456.94 & -0.72 \\
\hline 15 & $v$ & -393.96 & -395.46 & -0.63 \\
\hline 16 & Null model ${ }^{\mathrm{e}}$ & -375.73 & -376.37 & -0.60 \\
\hline
\end{tabular}

${ }^{a}$ All models included intercept, biofix $=1$ January, $T_{\text {base }}=0^{\circ} \mathrm{C}$.

${ }^{\mathrm{b}}$ DIC, deviance information criterion.

${ }^{c}$ WAIC, Watanabe-Akaike information criterion.

${ }^{\mathrm{d}}$ LCPO, logarithmic conditional predictive ordinate.

${ }^{\mathrm{e}}$ Null model includes only the intercept. 
models included all three fixed effects, ADD, ADDvpd, and ADDwet, but they were not further considered because the Pearson correlation coefficient between ADDvpd and ADDwet was 0.85, indicating potential problems of multicollinearity. The selected model (number 1 in Table 1), with the lowest values of DIC, WAIC, and LCPO, included the fixed effects ADD and ADDvpd and the random effect year $(v)$. Linear regression of the median posterior predictive distribution against observed values accounted for $>95 \%$ of the total variance $\left(R^{2}=0.98\right)$, with an intercept of 0.025 and a slope of 0.950 , respectively (Fig. 2). The MAE for this model was 0.042 , and the RMSE was 0.062. Patterns of serial correlation were not detected when the Pearson's residuals were plotted.

In the selected model, both ADD and ADDvpd were relevant. The parameter for the fixed effect ADD had a median posterior distribution of 0.293 with a $95 \%$ credible interval $(0.278,0.308)$, not overlapping with zero (Table 2). The parameter for the fixed effect ADDvpd had a median posterior distribution of 0.442 with a $95 \%$ credible interval $(0.313,0.575)$, also not overlapping with zero.

The posterior distribution of the two hyperparameters was also computed (Table 2). Note that the posterior distribution median of the dispersion parameter $\phi$ (inversely proportional to the beta variance) was 26.10, showing a low variation of the response. However, in the case of the random effect, the precision $\tau$, the inverse of the random effect variance, had a posterior distribution median of 7.48. This indicates that the random effect year is capturing variability that covariates cannot explain, making it important to consider this effect in the model. The two fixed effects, ADD and ADDvpd, had positive effects on the expected cumulative proportion of $P$. nawae ascospores discharged from the leaf litter, so the cumulative proportion of ascospores increased when ADD and ADDvpd increased. Considering the median posterior predictive distribution, 5\% of $P$. nawae ascospores were discharged from 995

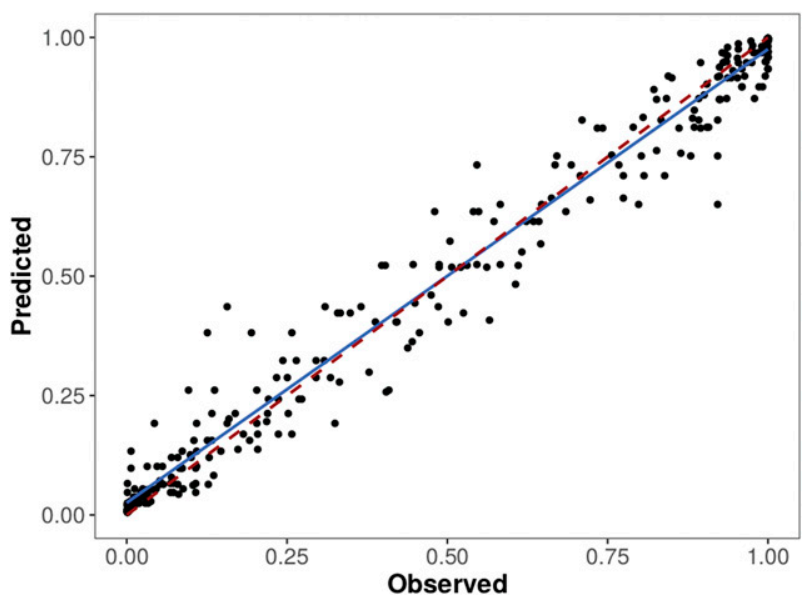

Fig. 2. Linear regression between observed values and the median of the posterior predictive distribution for the model of the cumulative proportion of Plurivorosphaerella nawae ascospores discharged from persimmon leaf litter (black dots), which includes the fixed effects accumulated degree-days (ADDs), ADDs considering vapor pressure deficit (ADDvpd), and the random effect year $(v)$ in L'Alcúdia. The blue line is the regression line, and the red line is the $1: 1$ line. to $1,520^{\circ} \mathrm{C}$-days $\mathrm{ADD}$ and 190 to $545^{\circ} \mathrm{C}$-days $\mathrm{ADDvpd}$ (Fig. 3). At the other extreme, $95 \%$ of $P$. nawae ascospores were discharged from 2,585 to $3,260^{\circ} \mathrm{C}$-days $\mathrm{ADD}$ and 300 to $740^{\circ} \mathrm{C}$-days ADDvpd.

When the selected model was applied to the evaluation dataset (Table 3), values of MAE $>0.1$ were obtained in Moncada in 2012 (0.311), 2014 (0.128), and 2015 (0.275) and in Benimodo in 2010 (0.109). An MAE <0.05 was obtained in Guadassuar in 2010 (0.042) and in Moncada in 2013 (0.042). For the RMSE, values $>0.3$ were obtained only in Moncada in 2012 (0.371) and 2015 (0.334). RMSE values <0.1 were obtained in Moncada in 2013 (0.058), in Guadassuar in 2010 (0.062), and in Benimodo in 2011 (0.097). When the median of the posterior predictive distribution was linearly regressed against the observations, values of $R^{2}>0.90$ were obtained in all cases except in Moncada in 2012 (0.720) and 2015 (0.700), in Benimodo in 2010 (0.849), and in Guadassuar in 2011 (0.892). When plotting observed versus predicted values, these four location-year combinations also showed the poorest graphical fit (Fig. 4). In general, residuals were greater in the central part of the plot and lower at the extremes, coinciding with the beginning and end of the ascospore production period (Fig. 4). Considering all the orchards and years of the evaluation dataset, the model predicted 5 and $95 \%$ of ascospore discharge from 4 to 24 April and from 27 June to 18 July, respectively.

\section{DISCUSSION}

We propose a Bayesian beta regression framework to model the dynamics of inoculum production when dealing with proportion data. Traditional data transformations are not needed in beta regression, and thus model parameters can be interpreted in terms of the original data through the link function (Ferrari and Cribari-Neto 2004). The analysis is less sensitive to sample size, and posterior distributions are expected to concentrate well within the bounded range of proportions. Previous studies with beta regression in the context of plant pathology used frequentist inference and did not include random effects (Burman et al. 2017; Busby et al. 2013; Xu et al. 2019; Yellareddygari et al. 2016). In contrast to frequentist inference, where point estimates and confidence intervals are obtained for model parameters, the results of Bayesian inference are presented by their posterior distributions. By means of the Bayes theorem, these posterior distributions combine the prior knowledge about the parameters and the information gathered from experiments expressed via the likelihood.

Nevertheless, because no information was available for $P$. nawae, we used vague priors with a large variance, reflecting great uncertainty (Carlin and Louis 2008). The hierarchical structure enabled a more natural specification of the model to be obtained, particularly when, as in our case, random effects are included. Although complex models can be readily approached from a Bayesian perspective, the resulting posterior distributions of their parameters do not have a closed form, and numerical approaches such as MCMC generally are needed to approximate them (Gilks et al. 1996). The INLA approach (Rue et al. 2009) was used here instead of MCMC because of its higher computation efficiency and speed

TABLE 2. Model for the cumulative proportion of Plurivorosphaerella nawae ascospores discharged from persimmon leaf litter including the fixed effects accumulated degree-days (ADDs) and ADDs taking into account vapor pressure deficit (ADDvpd) and the random effect year $(v)$

\begin{tabular}{lccrrr}
\hline $\begin{array}{l}\text { Parameters and } \\
\text { hyperparameters }^{\mathrm{a}}\end{array}$ & Mean & $\mathrm{SD}$ & $Q_{0.025}$ & $Q_{0.5}$ & $Q_{0.975}$ \\
\hline Intercept & -8.099 & 0.351 & -8.800 & -8.096 & -7.410 \\
ADD & 0.293 & 0.007 & 0.278 & 0.293 & 0.308 \\
ADDvpd & 0.443 & 0.066 & 0.313 & 0.442 & 0.575 \\
$\phi$ & 26.196 & 2.481 & 21.601 & 0.293 \\
$\tau$ & 9.383 & 7.312 & 1.538 & 7.487 & 31.361 \\
\hline
\end{tabular}

${ }^{a}$ Mean, standard deviation (SD), quantiles $(Q)$ and mode for the parameters and hyperparameters. $\phi$ is the dispersion parameter of the likelihood, and $\tau$ is the precision of the random effect year. The $95 \%$ credible interval is defined by $Q_{0.025}$ and $Q_{0.975}$. 
of calculation, as well as its good behavior for beta regression models (Paradinas et al. 2018). Indeed, INLA is often preferred over MCMC for dealing with large datasets and more complex models, because of its high computational efficiency. In our case, the model for $P$. nawae could be further extended with interpolated environmental data at higher resolution, where the computational advantages of INLA may be useful. Finally, it is worth noting that few studies using INLA are available in plant disease epidemiology (Denis et al. 2018; Marçais et al. 2016; Martínez-Minaya et al. 2018).

In the model selected for $P$. nawae, ADD and ADDvpd were the covariates driving the maturation of ascospores (Table 2). $P$. nawae overwinters in the leaf litter as mycelia or pseudothecial primordia, which mature and form ascospores as temperatures rise in spring. Ascospores are then released when the pseudothecia have absorbed sufficient moisture (Kwon and Park 2004; Vicent et al. 2011, 2012). In Korea, Choi et al. (2018) related ADD with the cumulative proportion of $P$. nawae ascospores captured by spore traps. However, there are many examples in the literature for other ascomycetes indicating that models for ascospore maturation should be corrected for dry periods, by accumulating degree-days only when sufficient moisture was available in leaf litter. Navas-Cortés et al. (1998b) considered ADD only on rainy days $(\geq 1 \mathrm{~mm})$ in order to predict the maturation of Didymella rabiei pseudothecia in chickpea in Spain. This study indicated that rain was essential for the
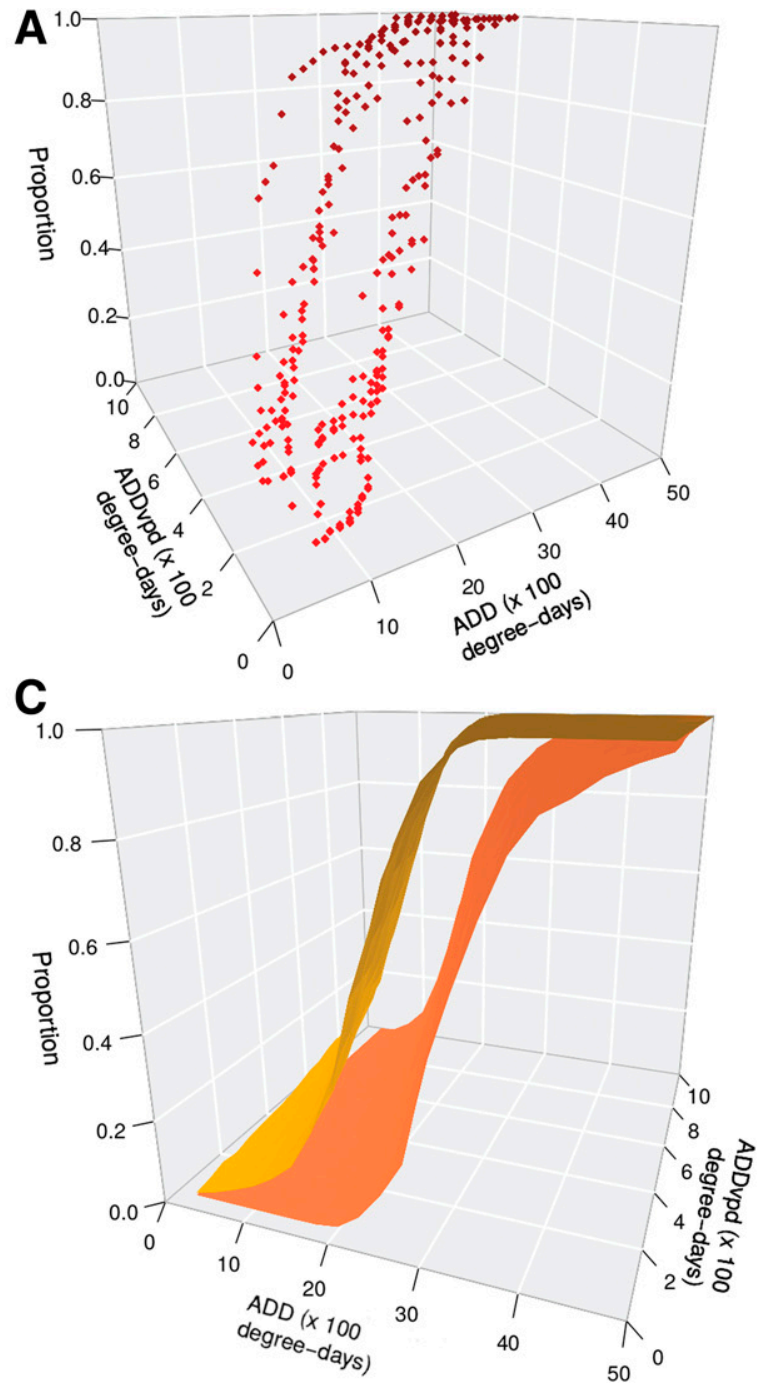

synchronization between $D$. rabiei ascospore availability and vegetative growth of the host. In Norway, Stensvand et al. (2005) improved model accuracy for Venturia inaequalis ascospore maturity in dry years by halting degree-day accumulation if 7 consecutive days without rain occurred. When comparing models for $V$. inaequalis ascospore maturation in different areas, Eikemo et al. (2011)

TABLE 3. Mean absolute error (MAE) and root mean square error (RMSE) for the model of the cumulative proportion of Plurivorosphaerella nawae ascospores discharged from persimmon leaf litter, which includes the fixed effects accumulated degree-days (ADDs), ADDs considering vapor pressure deficit, and the random effect year in Benimodo, Villanueva de Castellón, Guadassuar, and Moncada (Spain)

\begin{tabular}{lcccc}
\hline Location & Year & MAE & RMSE & $R^{2 \mathrm{a}}$ \\
\hline Benimodo & 2010 & 0.109 & 0.189 & 0.849 \\
& 2011 & 0.073 & 0.097 & 0.946 \\
Villanueva de Castellón & 2010 & 0.072 & 0.119 & 0.934 \\
& 2011 & 0.070 & 0.114 & 0.972 \\
Guadassuar & 2010 & 0.042 & 0.062 & 0.981 \\
& 2011 & 0.094 & 0.156 & 0.892 \\
Moncada & 2012 & 0.311 & 0.371 & 0.720 \\
& 2013 & 0.042 & 0.058 & 0.979 \\
& 2014 & 0.128 & 0.165 & 0.917 \\
& 2015 & 0.275 & 0.334 & 0.700 \\
\hline
\end{tabular}

${ }^{a}$ Values of $R^{2}$ for the linear regression between observed values and the median posterior predictive distribution.

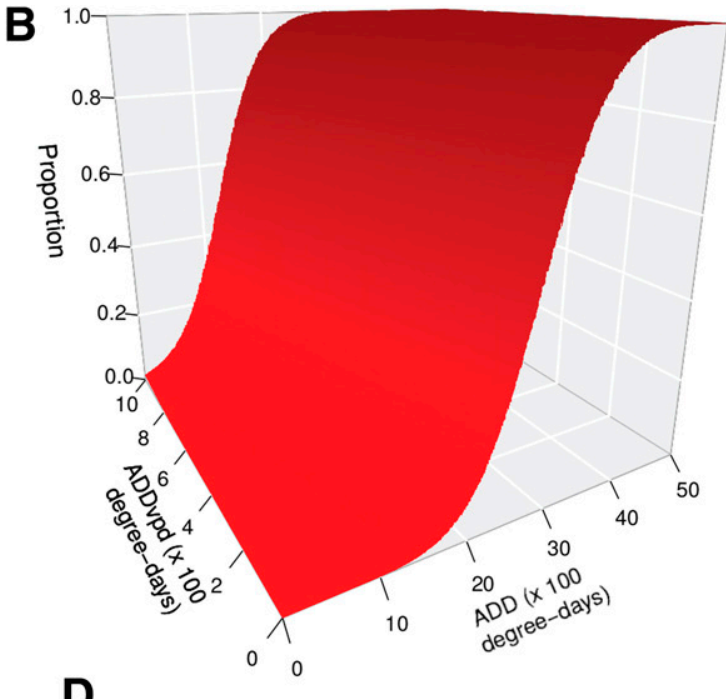

D

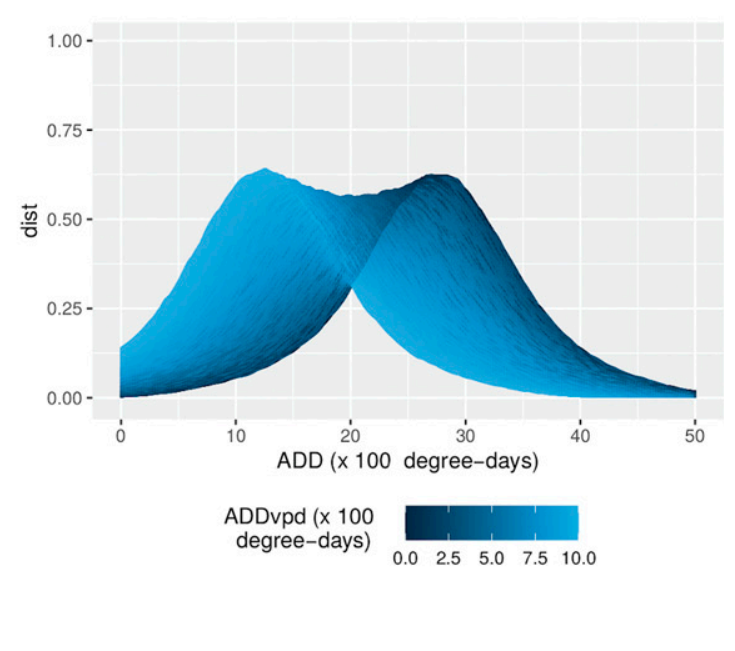

Fig. 3. Model for the cumulative proportion of Plurivorosphaerella nawae ascospores discharged from persimmon leaf litter in L'Alcúdia based on accumulated degree-days (ADDs) and ADDs considering vapor pressure deficit (ADDvpd). A, Data; B, median posterior predictive distribution; C, 95\% credible intervals; and $\mathbf{D}$, width of the $95 \%$ credible interval. 
indicated that those adjusted for dry periods were consistently the most accurate predictors of ascospore depletion.

Interestingly, ADDvpd was more relevant in the model for $P$. nawae than ADDwet, which also included the effect of rain $(\geq 0.2$ $\mathrm{mm}$ ) (Table 1). During the study period, dew resulting from low vpd was far more common than rain (Fig. 1A). In the case of $P$. nawae, wetness induced by dew was not sufficient for substantial ascospore discharge (Vicent et al. 2011), but in the absence of rain it may favor pseudothecial development and subsequent ascospore maturation. This was described by Rossi et al. (1999) for $V$. inaequalis in Italy, where models accounting for leaf litter wetness significantly improved estimates of airborne ascospores. Furthermore, Mondal and Timmer (2002) demonstrated that alternate wetting and drying of the leaf litter was necessary for the formation of pseudothecia of Zasmidium citri-griseum.

The selection of the date from which degree-days are accumulated (i.e., biofix) has been pointed out as a critical factor in the models for ascospore maturation and release. In some cases, a date
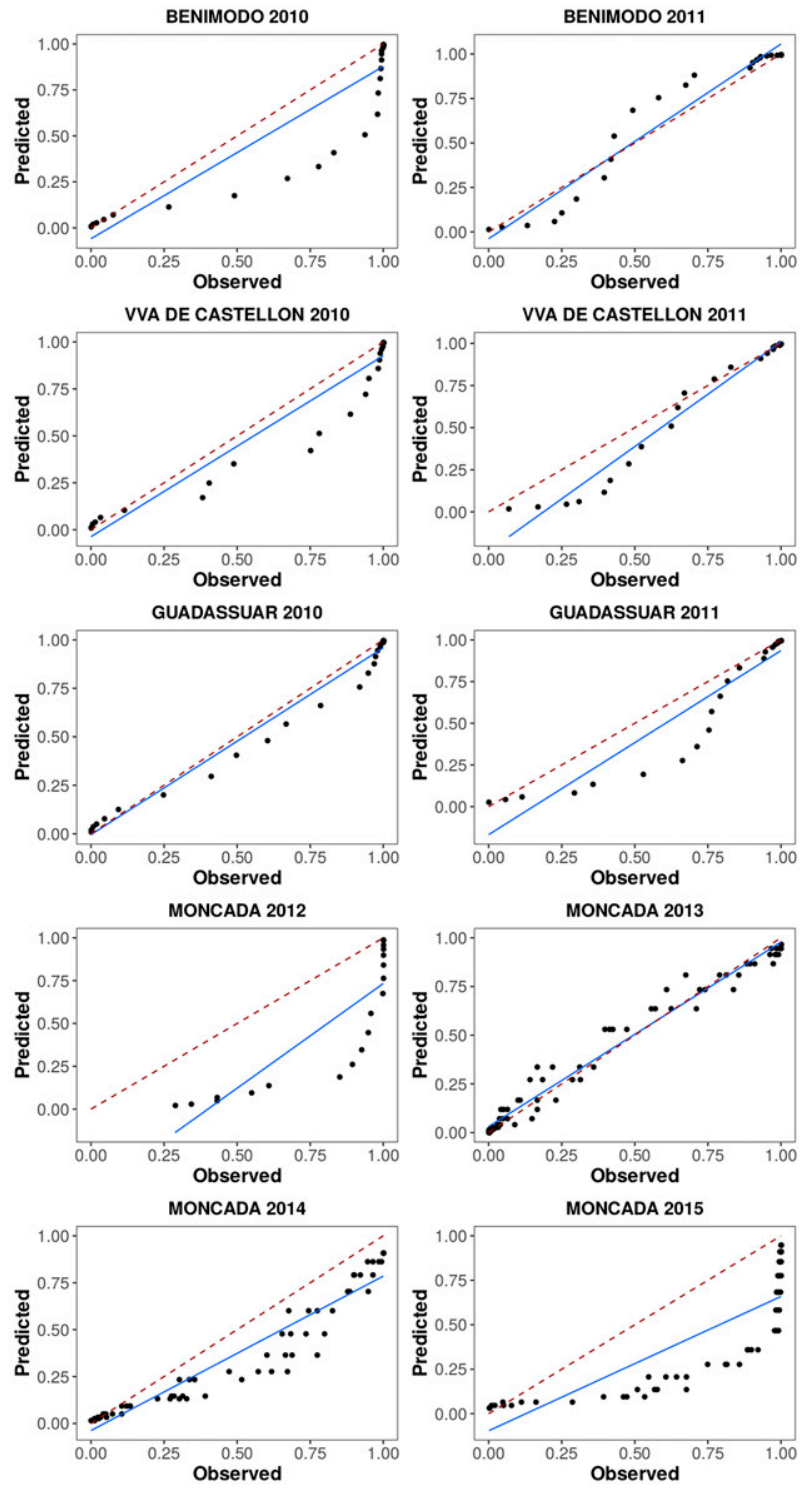

Fig. 4. Linear regression between observed values and the median of the posterior predictive distribution for the model of the cumulative proportion of Plurivorosphaerella nawae ascospores discharged from persimmon leaf litter (black dots), which includes the fixed effects accumulated degree-days (ADD), ADD, considering vapor pressure deficit (ADDvpd), and the random effect year $(v)$ in Benimodo, Villanueva de Castellón, Guadassuar, and Moncada. The blue solid line is the regression line, and the red dashed line is the $1: 1$ line. was chosen based on a specific phenological stage of the host, such as bud break or green tip (Eikemo et al. 2011; MacHardy and Gadoury 1985). However, the synchrony between host and fungal phenology may differ between regions. Often, the date of detection of the first mature pseudothecia or the first ascospore trapped has been used as the biofix (Eikemo et al. 2011; Spotts and Cervantes 1994). Nevertheless, this approach relies on the sensitivity of the detection methods used and, more importantly, requires leaf litter sampling or deployment of spore traps. Both methods are time- and resource-consuming, limiting the extent and density of the monitoring network. The most convenient approach to set the biofix is to use a fixed calendar date (James and Sutton 1982a), but it was argued that this does not take into account the climatic differences between regions (Llorente and Montesinos 2004). Roubal and Nicot (2016) used numerical optimization to define a single calendar date (1 January) as the biofix for $V$. inaequalis. Choi et al. (2018) used ADD from 1 May as the biofix to estimate the cumulative percentage of $P$. nawae ascospores captured by spore traps in Korea. In our case, 1 January was also chosen as the biofix for the production of $P$. nawae ascospores in the leaf litter because, in our conditions, persimmon trees attain complete leaf fall around this date, and so all the leaves are on the orchard floor with undifferentiated ascocarps.

As for other ascomycetes, our model for $P$. nawae considered temperature and moisture covariates as having a continuous positive effect on ascospore development (Fig. 3). However, the process resulting in ascospore formation in the leaf litter can be divided into different phases, which may have distinct temperature and moisture requirements. For D. rabiei, Gamliel-Atinsky et al. (2005) defined the pseudothecium ontogeny followed by initiation of asci and ascospores, and finally ascospore maturation. Navas-Cortés et al. (1998a) indicated that moisture was essential for pseudothecium ontogeny in D. rabiei, whereas cool temperatures were needed for the initiation of asci and ascospores. In fact, low temperatures are generally needed for the onset of sexual reproduction in many ascomycetes (Scherm et al. 2001; Trapero-Casas and Kaiser 1992). James and Sutton (1982b) indicated that the development of asci and ascospores in $V$. inaequalis began in spring, after a dormant period that was not influenced by temperature or moisture levels. Then, rapid maturation of ascospores was favored by moisture and increasing temperatures. Gadoury and MacHardy (1982a) indicated that the productivity of $V$. inequalis pseudothecia and the rate of ascus maturation were inversely proportional to temperatures from 4 to $20^{\circ} \mathrm{C}$. However, the rate of ascospore maturation was directly proportional to temperature within this range.

Roubal and Nicot (2016) related temperature to ascospore production of $V$. inaequalis and obtained better results when using a nonlinear unimodal function of thermal time compared with ADD. This unimodal function accounted for reduced effects of low and high temperatures on ascospore production. This type of unimodal response to temperature has been reported for some ascomycetes and ectotherms in general (Naseri et al. 2008; Trudgill et al. 2005). Nevertheless, the relationship between the rate of development and temperature is often linear over much of the range up to the thermal optimum, and thus ADDs are usually considered for thermal time calculations (Trudgill et al. 2005), in some cases lowering ADD values for temperatures above the optimum. In any case, knowledge of the temperature and moisture requirements for each phase of ascospore formation in $P$. nawae may be helpful in developing models with improved performance and better transferability to other areas.

Our models also corroborated previous studies in Spain indicating that $P$. nawae adapted to semiarid conditions by advancing the period of ascospore production to escape from the typical Mediterranean rainless summer. Consequently, ascospore production coincides with rains in spring, from March to June, under more favorable conditions for infection. On the other hand, low winter temperatures in Korea delayed ascospore release until June to 
August, thus synchronizing with the abundant summer rains typical in this area (Choi et al. 2018; Kang et al. 1993; Kwon et al. 1995; Kwon and Park 2004).

In previous studies, discharge tests allowed detection of mature ascospores of $P$. nawae in the leaf litter before they were released into the air in the orchard (Vicent et al. 2012). Similar results were reported for Sphaerulina musiva in poplar, where peak ascospore production in leaf litter measured with discharge tests occurred 7 days earlier than peak airborne ascospores (Luley and McNabb 1991). However, when comparing different methods to estimate the maturity and release of $V$. inaequalis ascospores, Gadoury et al. (2004) found that cumulative ascospore release in discharge tests from the leaf litter lagged behind that measured in the air of the orchard by spore traps. This time lag was attributed mainly to litter decay, which progressively reduced the leaf litter area on the orchard floor and subsequently the overall ascospore population in the air (Gadoury and MacHardy 1982a; Gadoury et al. 2004). This time lag may be even larger when a fixed leaf area sample instead of a number of leaves is used in discharge tests. In contrast to apple leaves, persimmon leaves are typically coriaceous, and no substantial degradation of the leaf litter was observed under the conditions of our study. Indeed, discharge tests from the leaf litter are effectively used by advisory services in Spain to predict airborne inoculum availability and schedule fungicide sprays for CLS management.

One of the aims of models for ascospore maturation is to predict the duration of the period for primary inoculum, when fungicide applications are generally needed. Thus, the practical performance of some of these models relies on their ability to accurately predict ascospore onset and depletion more than the discharge pattern during the ascosporic season (Eikemo et al. 2011; Gadoury et al. 2004). In the case of $P$. nawae in Spain, no conidia have been observed, and infections were caused by ascospores formed in the leaf litter (Vicent et al. 2012). Infections occur through the whole ascosporic season, and trees must be continuously protected with fungicides during this period. Spray frequency is then determined based on fungicide persistence (Garcerá et al. 2020). Therefore, accurate predictions of the beginning and end of the ascospore production period are important for designing efficient fungicide spray programs for $P$. nawae. Interestingly, when the beta regression model for $P$. nawae was evaluated in different orchards, the highest accuracy was obtained at the onset and depletion of ascospore production (Fig. 4).

The model was developed and evaluated in orchards of the cultivar Rojo Brillante, which represents $>90 \%$ of persimmons grown in Spain (Perucho 2015). Likewise, all orchards were drip-irrigated, because this is the most common system today (Intrigliolo et al. 2015). Therefore, the model can be implemented to predict the ascosporic season and assist the advisory services and persimmon growers in optimizing fungicide spray programs for CLS control in Spain. The model can be further improved by including environmental and ascospore dynamics data from more orchards and years, considering also other persimmon cultivars and different agronomic practices. This same modeling framework can be extended to other ascomycetes and fungal plant pathogens in general as long as inoculum dynamics are expressed as proportion data. Data and code are provided at https://bitbucket.org/joaquin-martinez-minaya/ betapathogen.

\section{ACKNOWLEDGMENTS}

We thank the editor and the reviewers for their careful reading of our manuscript and their valuable comments and suggestions.

\section{LITERATURE CITED}

Bassimba, D., Mira, J., Sedano, M., and Vicent, A. 2017. Control and yield loss modelling of circular leaf spot of persimmon caused by Mycosphaerella nawae. Ann. Appl. Biol. 170:391-404.
Berbegal, M., Mora-Sala, B., and García-Jiménez, J. 2013. A nested-polymerase chain reaction protocol for the detection of Mycosphaerella nawae in persimmon. Eur. J. Plant Pathol. 137:273-281.

Burman, E., Ackerman, J. D., and Tremblay, R. L. 2017. Invasive Syzygium jambos trees in Puerto Rico: no refuge from guava rust. J. Trop. Ecol. 33: 205-212.

Busby, P. E., Zimmerman, N., Weston, D. J., Jawdy, S. S., Houbraken, J., and Newcombe, G. 2013. Leaf endophytes and Populus genotype affect severity of damage from the necrotrophic leaf pathogen, Drepanopeziza populi. Ecosphere 4:1-12.

Carlin, B. P., and Louis, T. A. 2008. Bayesian Methods for Data Analysis. Chapman and Hall/CRC, Boca Raton, FL.

Choi, O., Park, J. J., Kang, B., Lee, Y., Park, J., Kwon, J. H., and Kim, J. 2018. Evaluation of ascospore prediction model for circular leaf spot caused by Mycosphaerella nawae of persimmon. J. Agr. Life Sci. 52:13-19.

Clark, J. S. 2005. Why environmental scientists are becoming Bayesians. Ecol. Lett. 8:2-14.

Cooley, D. R., Lerner, S. M., and Tuttle, A. F. 2007. Maturation of thyriothecia of Schizothyrium pomi on the reservoir host Rubus allegheniensis. Plant Dis. 91:136-141.

De Wolf, E. D., and Isard, S. A. 2007. Disease cycle approach to plant disease prediction. Annu. Rev. Phytopathol. 45:203-220.

Denis, M., Cochard, B., Syahputra, I., De Franqueville, H., and Tisné, S. 2018. Evaluation of spatio-temporal Bayesian models for the spread of infectious diseases in oil palm. Spat. Spatio-Temporal Epidemiol. 24:63-74.

Eikemo, H., Gadoury, D., Spotts, R., Villalta, O., Creemers, P., Seem, R., and Stensvand, A. 2011. Evaluation of six models to estimate ascospore maturation in Venturia pyrina. Plant Dis. 95:279-284.

Ferrari, S. L. P., and Cribari-Neto, F. 2004. Beta regression for modelling rates and proportions. J. Appl. Stat. 31:799-815.

Gadoury, D., and MacHardy, W. 1982a. Effects of temperature on the development of pseudothecia of Venturia inaequalis. Plant Dis. 66:464-468.

Gadoury, D. M., and MacHardy, W. E. 1982b. A model to estimate the maturity of ascospores of Venturia inaequalis. Phytopathology 72:901904.

Gadoury, D. M., Seem, R. C., MacHardy, W. E., Wilcox, W. F., Rosenberger, D. A., and Stensvand, A. 2004. A comparison of methods used to estimate the maturity and release of ascospores of Venturia inaequalis. Plant Dis. 88:869-874.

Gamliel-Atinsky, E., Shtienberg, D., Vintal, H., Nitzni, Y., and Dinoor, A. 2005. Production of Didymella rabiei pseudothecia and dispersal of ascospores in a Mediterranean climate. Phytopathology 95:1279-1286.

Garcerá, C., Vicent, A., and Chueca, P. 2020. Effect of spray volume, application timing and droplet size on spray distribution and control efficacy of different fungicides against circular leaf spot of persimmon caused by Plurivorosphaerella nawae. Crop Prot. 130:105072.

Geisser, S. 1980. Discussion on sampling and Bayes' inference in scientific modeling and robustness (by gep box). J. R. Stat. Soc. B 143:416-417.

Gilks, W. R., Richardson, S., and Spiegelhalter, D. 1996. Markov Chain Monte Carlo in Practice. Chapman and Hall/CRC, Boca Raton, FL.

Gómez-Rubio, V. 2020. Bayesian Inference with INLA. CRC Press, Boca Raton, FL.

Hassan, O., and Chang, T. 2019. Phylogenetic and morphological reassessment of Mycosphaerella nawae, the causal agent of circular leaf spot in persimmon. Plant Dis. 103:200-213.

Heinze, G., Wallisch, C., and Dunkler, D. 2018. Variable selection: A review and recommendations for the practicing statistician. Biometrical J. 60:431-449.

Ikata, S., and Hitomi, T. 1929. Studies on circular leaf spot of persimmon caused by Mycosphaerella nawae [in Japanese]. Spec. Bull. Okayama Pref. Agric. Exp. Stn. 33:1-36.

Intrigliolo, D. S., Besada, C., Salvador, A., and Bonet, L. 2015. Manejo del riego. Necesidades hídricas del caqui y respuestas al estrés hídrico. Pages 121-138 in: El Cultivo del Caqui. M. L. Badenes, D. S. Intrigliolo, A. Salvador, and A. Vicent, eds. Generalitat Valenciana, València.

James, J., and Sutton, T. 1982a. A model for predicting ascospore maturation of Venturia inaequalis. Phytopathology 72:1081-1085.

James, J., and Sutton, T. 1982b. Environmental factors influencing pseudothecial development and ascospore maturation of Venturia inaequalis. Phytopathology 72:1073-1080.

Kang, S., Kwon, J., Lee, Y., and Park, C. 1993. Effects of meteorological factors on perithecial formation and release of ascospores of Mycosphaerella nawae from the overwintered persimmon [in Korean, abstract in English]. RDA J. Agr. Sci. Crop Prot. 35:337-343.

Kwon, J., Kang, S., Chung, B., and Park, C. 1995. Environmental factors affecting ascospore release of Mycosphaerella nawae, the causal organism of the spotted leaf casting of persimmon [in Korean, abstract in English]. Korean J. Plant Pathol. 11:344-347.

Kwon, J. H., Kang, S. W., Park, C. S., and Kim, H. K. 1998. Microscopic observation of the pseudothecial development of Mycosphaerella nawae 
on persimmon leaves infected by ascospore and conidia [in Korean, abstract in English]. Korean J. Plant Pathol. 14:408-412.

Kwon, J. H., and Park, C. S. 2004. Ecology of disease outbreak of circular leaf spot of persimmon and inoculum dynamics of Mycosphaerella nawae [in Korean, abstract in English]. Res. Plant Dis. 10:209-216.

Legler, S. E., Caffi, T., and Rossi, V. 2014. A model for the development of Erysiphe necator chasmothecia in vineyards. Plant Pathol. 63:911-921.

Llorente, I., and Montesinos, E. 2004. Development and field evaluation of a model to estimate the maturity of pseudothecia of Pleospora allii on pear. Plant Dis. 88:215-219.

Luley, C. J., and McNabb, H. S., Jr. 1991. Estimation of seasonal ascospore production of Mycosphaerella populorum. Can. J. For. Res. 21:1349-1353.

MacHardy, W. E., and Gadoury, D. M. 1985. Forecasting the seasonal maturation of ascospores of Venturia inaequalis. Phytopathology 75:381-385.

Malagón, J. 2015. Diseño y manejo de la plantación del caqui. Pages 81-99 in: El Cultivo del Caqui. M. L. Badenes, D. S. Intrigliolo, A. Salvador, and A. Vicent, eds. Generalitat Valenciana, València.

Marçais, B., Husson, C., Godart, L., and Cael, O. 2016. Influence of site and stand factors on Hymenoscyphus fraxineus-induced basal lesions. Plant Pathol. 65:1452-1461.

Martínez-Minaya, J., Conesa, D., López-Quílez, A., and Vicent, A. 2018. Spatial and climatic factors associated with the geographical distribution of citrus black spot disease in South Africa. A Bayesian latent Gaussian model approach. Eur. J. Plant Pathol. 151:991-1007.

Mondal, S., and Timmer, L. 2002. Environmental factors affecting pseudothecial development and ascospore production of Mycosphaerella citri, the cause of citrus greasy spot. Phytopathology 92:1267-1275.

Naseri, B., Davidson, J., and Scott, E. 2008. Effect of temperature, cultivar and plant tissue on the germination of, and hyphal growth from, ascospores of Leptosphaeria maculans. Australas. Plant Pathol. 37:365-372.

Navas-Cortés, J., Trapero-Casas, A., and Jiménez-Díaz, R. 1998a. Influence of relative humidity and temperature on development of Didymella rabiei on chickpea debris. Plant Pathol. 47:57-66.

Navas-Cortés, J., Trapero-Casas, A., and Jiménez-Díaz, R. 1998b. Phenology of Didymella rabiei development on chickpea debris under field conditions in Spain. Phytopathology 88:983-991.

Paradinas, I., Pennino, M. G., López-Quílez, A., Marín, M., Bellido, J. M., and Conesa, D. 2018. Modelling spatially sampled proportion processes. Revstat Stat. J. 16:71-86.

Perucho, J. 2015. El cultivo del caqui. Antecedentes e importancia económica. Pages 17-34 in: El Cultivo del Caqui. M. L. Badenes, D. S. Intrigliolo, A. Salvador, and A. Vicent, eds. Generalitat Valenciana, València.

R Core Team. 2020. R: A Language and Environment for Statistical Computing. R Foundation for Statistical Computing, Vienna, Austria.

Roos, M., and Held, L. 2011. Sensitivity analysis in Bayesian generalized linear mixed models for binary data. Bayesian Anal. 6:259-278.

Rossi, V., Ponti, I., Marinelli, M., Giosue, S., and Bugiani, R. 1999. Field evaluation of some models estimating the seasonal pattern of airborne ascospores of Venturia inaequalis. J. Phytopathol. 147:567-575.

Rossi, V., Salinari, F., Pattori, E., Giosuè, S., and Bugiani, R. 2009. Predicting the dynamics of ascospore maturation of Venturia pirina based on environmental factors. Phytopathology 99:453-461.
Roubal, C., and Nicot, P. 2016. Apple scab: Numerical optimization of a new thermal time scale and application for modelling ascospore release in southern France. Plant Pathol. 65:79-91.

Rue, H., Martino, S., and Chopin, N. 2009. Approximate Bayesian inference for latent Gaussian models by using integrated nested Laplace approximations. J. Roy. Stat. Soc. B Met. 71:319-392.

Scherm, H., Savelle, A., and Pusey, P. 2001. Interactions between chill-hours and degree-days affect carpogenic germination in Monilinia vacciniicorymbosi. Phytopathology 91:77-83.

Simpson, D., Rue, H., Riebler, A., Martins, T. G., and Sørbye, S. H. 2017. Penalising model component complexity: A principled, practical approach to constructing priors. Stat. Sci. 32:1-28.

Smithson, M., and Verkuilen, J. 2006. A better lemon squeezer? Maximumlikelihood regression with beta-distributed dependent variables. Psychol. Methods 11:54-71.

Spiegelhalter, D. J., Best, N. G., Carlin, B. P., and Van Der Linde, A. 2002. Bayesian measures of model complexity and fit. J. Roy. Stat. Soc. B Met. 64:583-639.

Spotts, R., and Cervantes, L. A. 1994. Factors affecting maturation and release of ascospores of Venturia pirina in Oregon. Phytopathology 84:260-263.

Stensvand, A., Eikemo, H., Gadoury, D. M., and Seem, R. C. 2005. Use of a rainfall frequency threshold to adjust a degree-day model of ascospore maturity of Venturia inaequalis. Plant Dis. 89:198-202.

Tierney, L., and Kadane, J. B. 1986. Accurate approximations for posterior moments and marginal densities. J. Am. Stat. Assoc. 81:82-86.

Trapero-Casas, A., and Kaiser, W. 1992. Development of Didymella rabiei, the teleomorph of Ascochyta rabiei, on chickpea straw. Phytopathology 82:1261-1266.

Trudgill, D., Honek, A., Li, D., and Van Straalen, N. 2005. Thermal time: concepts and utility. Ann. Appl. Biol. 146:1-14.

Vicent, A., Bassimba, D., and Intrigliolo, D. 2011. Effects of temperature, water regime and irrigation system on the release of ascospores of Mycosphaerella nawae, causal agent of circular leaf spot of persimmon. Plant Pathol. 60:890-908.

Vicent, A., Bassimba, D. D., Hinarejos, C., and Mira, J. L. 2012. Inoculum and disease dynamics of circular leaf spot of persimmon caused by Mycosphaerella nawae under semi-arid conditions. Eur. J. Plant Pathol. 134:289-299.

Villalta, O., Washington, W., Rimmington, G. M., and MacHardy, W. 2001. Environmental factors influencing maturation and release of ascospores of Venturia pirina in Victoria, Australia. Aust. J. Agric. Res. 52:825-837.

Watanabe, S. 2010. Asymptotic equivalence of Bayes cross validation and widely applicable information criterion in singular learning theory. J. Mach. Learn. Res. 11:3571-3594.

West, J. S., and Kimber, R. B. E. 2015. Innovations in air sampling to detect plant pathogens. Ann. Appl. Biol. 166:4-17.

Whiteside, J. 1974. Possibilities of using ground sprays to control citrus greasy spot. P. Fl. St. Hortic. Soc. 86:19-23.

$\mathrm{Xu}, \mathrm{X}$., Ma, L., and $\mathrm{Hu}, \mathrm{X}$. 2019. Overwintering of wheat stripe rust under field conditions in the northwestern regions of China. Plant Dis. 103:638-644.

Yellareddygari, S. K., Pasche, J. S., Taylor, R. J., Hua, S., and Gudmestad, N. C. 2016. Beta regression model for predicting the development of pink rot in potato tubers during storage. Plant Dis. 100:1118-1124. 